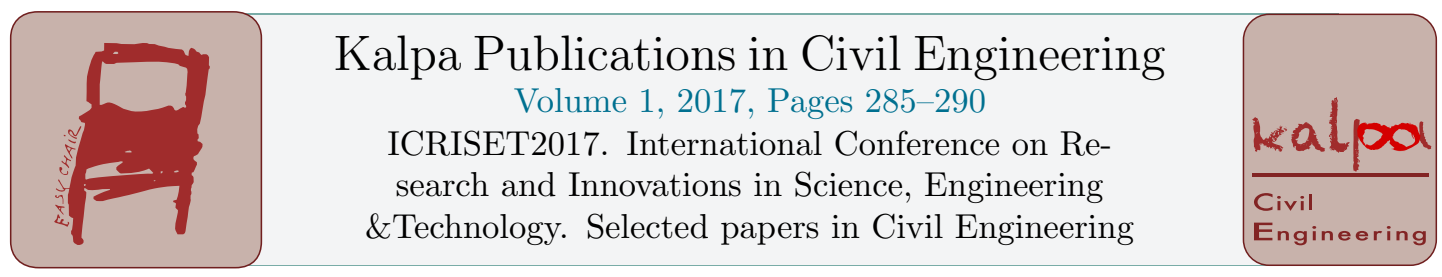

\title{
Feasibility of Utilization of Industrial Polyurethane (PU) Rubber Waste in Geopolymer Concrete
}

\author{
Jaydev Pandya ${ }^{1}$, Siddharth Shah ${ }^{2}$, Shemal Dave ${ }^{3}$ \\ ${ }^{1}$ PG Research Scholar, Department of civil engineering, Marwadi Education Foundation's \\ Group of Institutions, Rajkot, Gujarat, India \\ Jaydevpandya1993@gmail.com \\ ${ }^{2}$ Associate Professor,Head of Department civil engineering, Marwadi Education \\ Foundation's Group of Institutions, Rajkot, Gujarat, India \\ Siddharth.shah@marwadieducation.edu.in \\ ${ }^{3}$ Assistant Professor, Department of civil engineering, Marwadi Education Foundation's \\ Group of Institutions, Rajkot, Gujarat, India \\ Shemal2203@gmail.com
}

\begin{abstract}
Abstract - Concrete being most widely used construction material across the world need to be sustainable. This study aims at feasibility study the effects of addition of PU rubber in geopolymer concrete for its strength. PU rubber is formed by polymerization process. A long and low crosslinking chain gives stretchy polymer and a short and high crosslinking chain gives hard polymer. High amounts of crosslinking give tough or rigid polymers. Geopolymer concrete includes an alternate material i.e Fly ash in replacement of cement, as a binding material. Fly ash reacts with the alkaline activated solution i.e mixture of Sodium Hydroxide $(\mathrm{NaOH})$ and Sodium Silicate $\left(\mathrm{Na}_{2} \mathrm{SiO}_{3}\right)$ forming a gel which binds the aggregates thoroughly. Cubes of size $150 \mathrm{~mm} \times 150 \mathrm{~mm} \times 150 \mathrm{~mm}$ were casted and oven curing was done for 24 hour at $100^{\circ} \mathrm{C}$. Compression test was performed in hardened state, for different proportions of replacing the aggregate with PU rubber i.e. $5 \%, 10 \%, 15 \%, 20 \%$. Compressive strength test was performed at $7 \& 28$ days. Results were obtained and compared. Optimum mixes are Fly ash Coarse aggregate, Fine aggregate, Solution of $\mathrm{NaOH}$ and $\mathrm{Na}_{2} \mathrm{SiO}_{3}$ combined. Decrease in strength was observed at $7 \& 28$ days.
\end{abstract}

Keywords- Geopolymer concrete, Fly ash, Polyurethane Rubber (PU), Compressive Strength, Optimum mix. 


\section{INTRODUCTION}

Joseph Davidovits introduced the term geopolymer concrete first in 1978. Geopolymer concrete do not requires water for the bonding purpose instead alkaline solution of Sodium Hydroxide $(\mathrm{NaOH})$ and Sodium Silicate $(\mathrm{Na} 2 \mathrm{SiO} 3)$ is used. Geopolymer concrete represents a wide range of materials that are characterized networks of inorganic molecule. The fly ash contains high amount of Silica (Si) and Alumina (Al) that reacts with alkaline solution and forms a gel which binds the fine and coarse aggregates. Process of polymerization involves a quick chemical reaction $\mathrm{n}$ presence of alkaline condition on Si-Al minerals. Fly ash when reacts with Sodium Hydroxide and Sodium Silicate a material with ring structure of Si-O-Al-O bonds and three dimensional polymeric chain is obtained.

$$
\mathrm{Mn}\left[-\left\{\mathrm{SiO}_{2}\right\} \mathrm{z}-\mathrm{AlO}_{2}\right] \mathrm{n} \cdot \mathrm{wH}_{2} \mathrm{O}
$$

i.e. $\mathrm{M}$ - monovalent cation such as Sodium the symbol - indicates bond presence $\mathrm{n}$ - degree of polymerization

$\mathrm{z}-1,2,3,4$ or higher order.

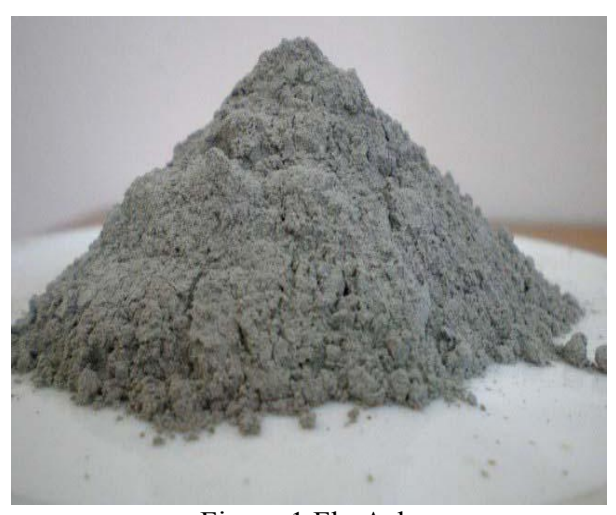

Figure 1 Fly Ash

Tabel-1 Constituents of fly ash

\begin{tabular}{|c|l|c|}
\hline Sr. No. & \multicolumn{1}{|c|}{ Test } & Result \\
\hline 1 & Loss on ignition & $<1 \%$ \\
\hline 2 & Silica as $\mathrm{SiO}_{2}$ & $62.57 \%$ \\
\hline 3 & Alumina as $\mathrm{Al}_{2} \mathrm{O}_{3}$ & $12.11 \%$ \\
\hline 4 & Magnesium as $\mathrm{MgO}$ & $0.85 \%$ \\
\hline 5 & Sulphur Trioxide $\mathrm{SO}_{3}$ & N/A \\
\hline 6 & Calcium as Cao & $8.18 \%$ \\
\hline 7 & Iron Oxide as $\mathrm{Fe}_{2} \mathrm{O}_{3}$ & N/A \\
\hline 8 & Alkalies & $0.007 \%$ \\
\hline 9 & Reactive Silica & $>20 \%$ \\
\hline
\end{tabular}

The class F fly ash was obtained from Thermal Power Station, Wanakbori, Gujarat, India. Khoa Tan Nguyen, et al.(2016) stated that for fly ash based geopolymer concrete compressive strength is in the range of 45-58 $\mathrm{MPa}$. [6]

A review of the literature revealed that several experimental studies have been performed on geopolymer concrete by mixing different kinds of rubber wastes.

Ampol Wongs et al. (2016) reported that for making of lightweight fly ash geopolymer concrete bottom ash fine and coarse aggregate can be used. For different ratio of NS/NH $0.5,1,1.5$ and L/A $0.70,0.75,080$. Compressive strengths and Splitting tensile strengths ranges $14.31-18.10 \mathrm{MPa}$ and 1.20-2.10 MPa. respectively. [1] 
Aniruddh et al. (2016) The comparison exhibited lower compressive and splitting-tensile strength than did normal concrete. resulted their study that the potential of using tyre chips and crumb rubber by as coarse aggregate in portland-cement concrete and in geopolymer concrete by the increase in size of the aggregate and it's ratio by weight. [2]

Yeonho Park et al. (2015) suggested that main objective was to promote the reuse of rubber, but the decrease in compressive strength of the geopolymer concrete was observed by gradual increase in content of crumb rubber with different ratios by weight [3]

Faiz Uddin et al. (2016) suggested that partial replacement of Natural coarse aggregate with Recycled coarse aggregate in geopolymer concrete of ratios $15 \%, 30 \%, 50 \%$ by weight the compressive strength decreases with increase in ratio. [5]

F. Pacheco-Torgal et al. (2012) suggested that Polyethylene Terepthalate bottles (PET) rubber is responsible for the lowest environmental impact. Replacing aggregates by tyre rubber and PET as coarse aggregate $(15-20 \mathrm{~mm})$ by $25 \%, 50 \%, 75 \%$ and fine aggregate $(2.4-4 \mathrm{~mm})$ by $15 \%, 50 \%, 75 \%$. Decrease in compressive strength was observed by $11.6 \%-47 \%$. [4]

\section{MATERAL PROPERTIES}

Otto Bayer and his coworkers at I.G. Farben in Leverkusen, Germany, produced the first polyurethanes in 1937. Polyurethanes commercially were available in 1952 and its flexible production began in 1954.

While most polyurethanes are thermosetting polymers that do not melt when heated, thermoplastic polyurethanes are also available. Polyurethane (PUR and PU) is a polymer composed of a chain of organic units joined by carbamate (urethane) links.

Then late in 1990s, the carbon dioxide, pentane, 1,1,1,2-tetrafluoroethane (HFC-134a) and 1,1,1,3,3pentafluoropropane (HFC-245fa) were widely used as blowing agents. Both the isocyanates and polyols used to make polyurethanes contain on average two or more functional groups.

Polyurethane polymers are formed by reacting an isocyanate with a polyol. The PU rubber is used for floor coatings, sole of shoes etc. The average production in India is estimated to reach 10000 tonnes per year by 2017 and annual production is about 10 million tonnes per year.

Table-2 Physical properties of PU RUBBER

\begin{tabular}{|c|c|c|c|c|c|}
\hline $\begin{array}{l}\text { SR. } \\
\text { NO. }\end{array}$ & PROPERTIES & UNIT & $\begin{array}{l}\text { Urethane } \\
\text { Rubber }\end{array}$ & $\begin{array}{c}\text { Urethane } \\
\text { Rubber } \\
\text { (Low } \\
\text { Repulsion) }\end{array}$ & $\begin{array}{c}\text { Urethane Rubber } \\
\text { (Super Low } \\
\text { Repulsion) }\end{array}$ \\
\hline 1 & Specific Gravity & --- & 1.131 & 1.03 & 1.02 \\
\hline 2 & Hardness & Shore A & 95 & 70 & 15 \\
\hline 3 & Tensile Strength & $\mathrm{MPa}$ & 44.1 & 11.8 & 0.6 \\
\hline 4 & Elongation & $\%$ & 400 & 250 & 445 \\
\hline 5 & Heat Resistance & ${ }^{\circ} \mathrm{C}$ & 70 & 70 & 80 \\
\hline
\end{tabular}




\begin{tabular}{|c|c|c|c|c|c|}
\hline 6 & Low Temperature & ${ }^{\circ} \mathrm{C}$ & -40 & -20 & -40 \\
\hline
\end{tabular}

Table-3 Chemical properties of PU RUBBER

\begin{tabular}{|c|c|c|}
\hline $\begin{array}{c}\text { SR. } \\
\text { NO. }\end{array}$ & CONSTITUENT & VALUE (\%) \\
\hline 1 & OCN & 87.91 \\
\hline 2 & $\mathrm{CH}_{2}$ & 4.70 \\
\hline 3 & $\mathrm{NH}_{2}$ & 0.97 \\
\hline 4 & $\mathrm{MgO}$ & 0.30 \\
\hline 5 & $\mathrm{Na}_{2} \mathrm{O}$ & 0.19 \\
\hline 6 & $\mathrm{~K}_{2} \mathrm{O}$ & 0.25 \\
\hline 7 & $\mathrm{TiO}_{2}$ & 0.15 \\
\hline
\end{tabular}

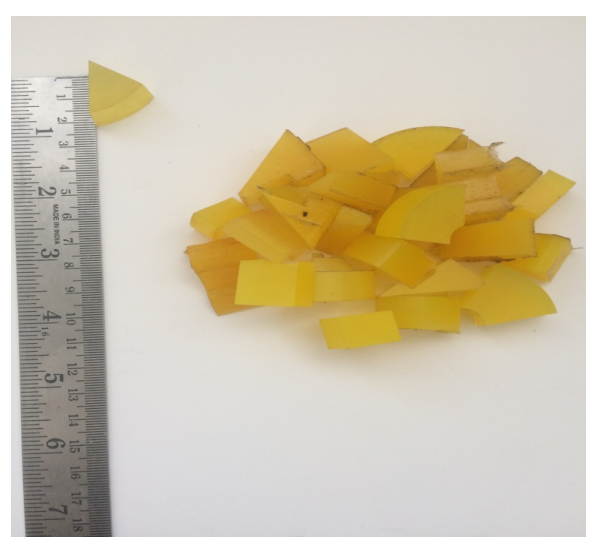

Figure 2 PU Rubber
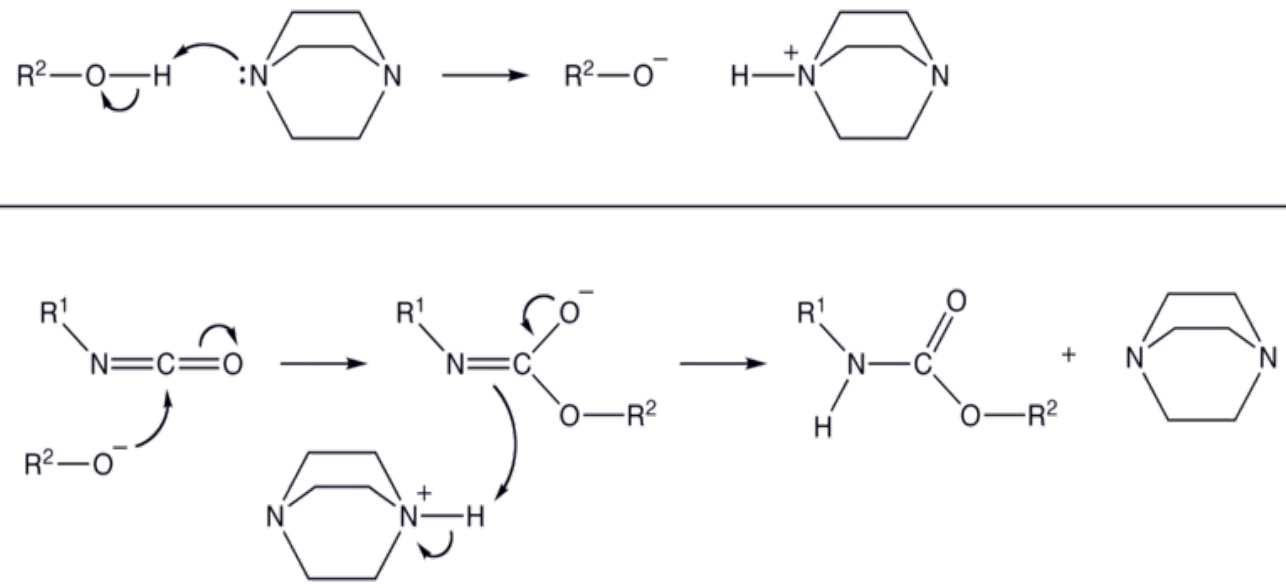

Figure 3 Chemical composition of PU rubber

\subsection{MATERIAL USED}

Fine aggregates and coarse aggregates which were locally approved were collected from a nearby Crusher Unit, Rajkot, Gujarat, India.

16 Molar solution was prepared for the use. Since the molecular weight of Sodium Hydroxide is 40, and in order to prepare 16 molar solution $16 \times 40=640$ grams of Sodium Hydroxide was dissolved in $1000 \mathrm{ml}$ of water. Sodium Hydroxide $(\mathrm{NaOH})$ in pellet form available in the local market is used. 
Sodium Silicate $\left(\mathrm{Na}_{2} \mathrm{SiO}_{3}\right)$ is commercially available in the market in form of thick liquid. A ratio of $\mathrm{SiO}_{2}$ to $\mathrm{Na} 2 \mathrm{O}$ is approximately 2 was used for $\mathrm{Na}_{2} \mathrm{SiO}_{3}$ solution.

\subsection{PROPORTIONS}

The previous studies on geopolymer concrete uses Fly Ash, Coarse aggregate, Fine aggregate, and solution of $\mathrm{NaOH}$ and $\mathrm{Na}_{2} \mathrm{SiO}_{3}$ for the mix. Four different mixes were prepared by replacing the Coarse aggregate $(20 \mathrm{~mm})$ by weight, by different proportions i.e. $5 \%, 10 \%, 15 \%, 20 \%$.

\subsection{PREPARATION OF ALKALINE SOLUTION}

The solution of sodium hydroxide and sodium silicate were mixed together one day or 24 hours before for use of preparing geopolymer concrete. The ratio of sodium silicate to sodium hydroxide solution was kept as $2.5 \%$ in this study.

\subsection{MIXING OF GEOPOLYMER CONCRETE}

The Geopolymer concrete was placed in $150 \mathrm{~mm} \times 150 \mathrm{~mm} \times 150 \mathrm{~mm}$ cube moulds in three layers and each layer was compacted with a $25 \mathrm{~mm}$ tamping rod by giving 25 blows on each layer. The fly ash, fine aggregates and coarse aggregates were hand mixed manually on a tray and then the alkaline solution was added to prepare the Geopolymer concrete.

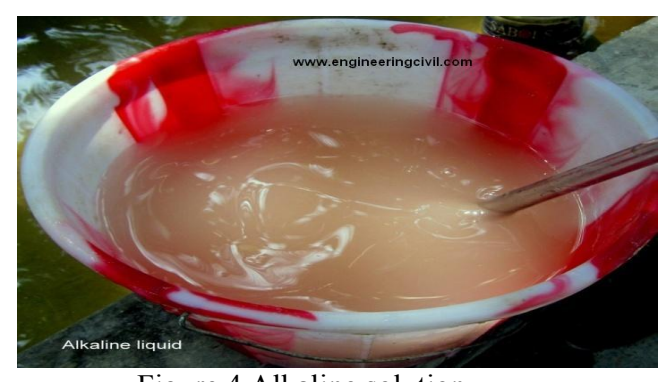

Figure 4 Alkaline solution

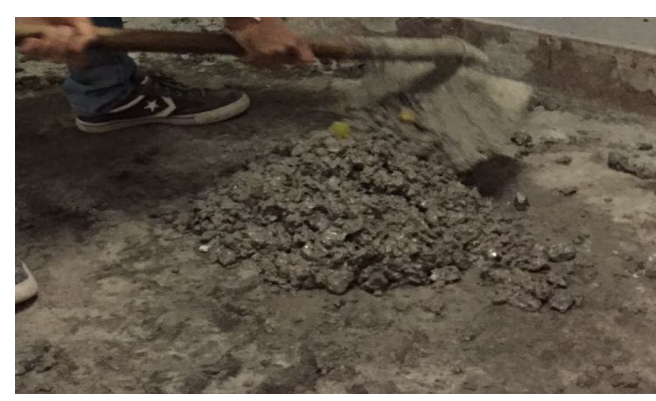

Figure 5 Mixing of Geopolymer concrete

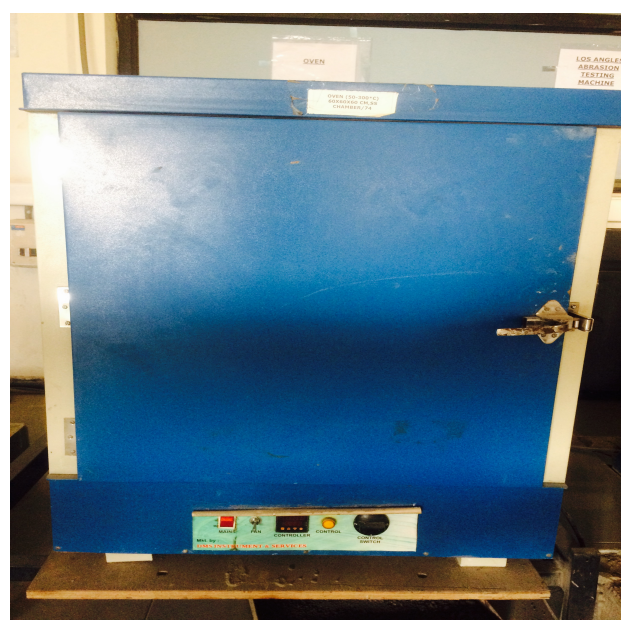

Figure 6 Oven curing 


\subsection{CURING}

Geopolymer concrete did not attain any strength at room temperature or by water curing as concluded in the past study. Geopolymer concrete will harden at oven curing or steam curing and the minimum curing period shall be 24 hours. The geopolymer concrete mould were then placed in an oven for the curing at temperature $100^{\circ} \mathrm{C}$ for 24 hours.

\subsection{Compressive Strength Test}

The specimens were tested for compressive strength using a calibrated compression testing machine of 2,000 KN capacities with Indian Standard test procedure. The results for 7-days and 28days were carried out.

Table-4 Compressive strength results

\begin{tabular}{|c|c|c|c|c|}
\hline $\begin{array}{c}\text { Mix } \\
\text { no. }\end{array}$ & Dosage & $\begin{array}{l}\text { PU } \\
\text { content }\end{array}$ & $\begin{array}{c}7- \\
\text { days }\end{array}$ & $\begin{array}{c}28- \\
\text { days }\end{array}$ \\
\hline 1 & GPC0 & $0 \%$ & 26.01 & 33.15 \\
\hline 2 & GPC5 & $5 \%$ & 14.36 & 31.93 \\
\hline 3 & GPC10 & $10 \%$ & 17.52 & 32.46 \\
\hline 4 & GPC15 & $15 \%$ & 17.93 & 32.71 \\
\hline 5 & GPC20 & $20 \%$ & 19.26 & 31.77 \\
\hline
\end{tabular}

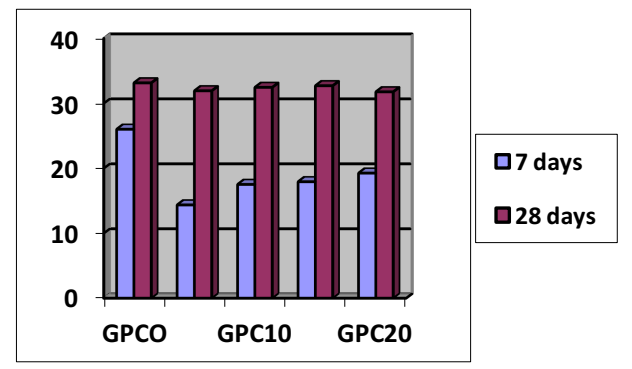

Figure 7 Compressive strength for different ratio

\section{CONCLUSION}

In this study it is concluded that by increasing the quantity of rubber and replacing it with different ratio i.e $5 \%, 10 \%, 15 \%, 25 \%, 50 \%$. The compressive strength gradually decreases. The compressive strength of GPC for 7 days as well as for 28 days decreases. High early strength as well as high performance was obtained in the Geopolymer concrete mix. The decrease in compressive strength was found beyond the strength obtained in normal optimum mix. Potential use of rubber cannot be used for the increasing compressive strength for concrete. This may be due to the improper bonding of PU with the mix and also due to increase in volume of voids in the aggregates. Potentially rubber is not a material to be used for the strength increasing factor for concrete.

\section{REFERENCES}

[1] Ampol Wongsa, Yuwadee Zaetang, Vanchai Sata, Prinya Chindaprasirt, "Properties of lightweight fly ash geopolymer concrete containing bottom ash as aggregates", Elsevier/Building and Construction materials, 2016.

[2] Aniruddh, Mr. Abhishek Kumar, Mohd. Afaque Khan, "Effect on compressive strength of concrete by using waste rubber as partial replacement of fine aggregate", International Research Journal of Engineering and Technology (IRJET) ,2016.

[3] Yeonho Park, Ali Abolmaali, Young Hoon Kim, Masoud Ghahremannejad, "Compressive strength of fly ashbased geopolymer concrete with crumb rubber partially replacing sand", Elsevier/Building and Construction materials, 2015.

[4] F. Pacheco-Torgal, Yining Ding, Said Jalali, "Properties and durability of concrete containing polymeric wastes (tyre rubber and polyethylene terephthalate bottles)", Elsevier/Building and Construction materials, 2015.

[5] Faiz Uddin ,Ahmed Shaikh, "Mechanical and durability properties of fly ash geopolymer concrete containing recycled coarse aggregates" ELSEVIER/Inter. Journal of suistainabe built environment ,2016.

[6] Khoa Tan Nguyen, Namshik Ahn, Tuan Anh Le, Kihak Lee, "Theoretical and experimental study on mechanical properties and flexural strength of fly ash-geopolymer concrete", Elsevier/Building and Construction materials, 2016. 